\title{
Editorial
}

\section{Special Issue on Risk Management Techniques for Catastrophic and Heavy-Tailed Risks}

\author{
Alejandro Balbás ${ }^{1}$ and José Garrido ${ }^{2}$ \\ ${ }^{1}$ University Carlos III of Madrid. C/ Madrid, 126. 28903 Getafe (Madrid, Spain); \\ E-Mail: alejandro.balbas@uc3m.es \\ ${ }^{2}$ Concordia University. Department of Mathematics and Statistics. 1455 de Maisonneuve Blvd. W., \\ Montreal, QC H3G 1M8, Canada; E-Mail: jose.garrido@ concordia.ca \\ * Author to whom correspondence should be addressed; E-Mail: alejandro.balbas@uc3m.es \\ Tel.: +34-91-6249636.
}

External Editor: Mogens Steffensen

Received: 4 November 2014 / Accepted: 5 November 2014 / Published: 14 November 2014

The publication of several special issues was part of the initiatives taken in 2013 to launch Risks as a new online journal. It seemed natural to devote one to this important, concrete and complex problem of managing catastrophic and heavy tailed risks. We received an enthusiastic response last spring to the call for invited and contributed research papers and are proud of the special issue now being published. The emphasis was put on quality rather than quantity; this special issue contains three invited and two contributed research papers.

The diversity of topics, techniques and perspectives studied in the last few years under this catastrophic and heavy-tailed risks theme has already led to the organization of several international workshops. The same diversity is illustrated here; the issue features research papers on recent methodological advances, as well as discussions on regulatory requirements, empirical issues or papers that establish further connections with other fields of applied probability, mathematics and statistics.

Among the three invited papers, in the first one Paul Embrechts, Giovanni Puccetti, Ludger Rüschendorf, Ruodu Wang, and Antonela Beleraj give an academic response to two recent regulatory documents, referred to as Basel 3.5. This is a very timely opinion piece that aims at stirring up the debate on the new proposals of the Basel Committee.

Then Hansjörg Albrecher, Christian Robert and Jef Teugels, in the second invited paper, give several results on normalised sums of the smallest and largest claims, from a portfolio of iid claims with slowly varying tails. 
In the third invited paper, Enrico Biffis and Erik Chavez present empirical evidence of heavy tails in commercial property losses. They propose the use of robust reserving and capital models.

In addition, a contributed paper by Sofiane Aboura, discusses the difficult topic of applying extreme value theory to raw returns data. He illustrates his proposal for a quantile regression model with the S\&P500 stock indexes from 1950 to 2013, that includes several stock market crashes, currency crises, the dot-com and real estate bubble burst, as well as the recent credit crunch and banking scare.

Finally, our own contributed paper looks at the challenging problem of finding alternative risk measures to VaR for risks with infinite expectations, such as those characterized by some Pareto distributions. A new partial extension method allows the introduction of coherent risk measures, even when expected losses are unbounded.

All the papers appearing in this special issue went through a refereeing process subject to the usual high standards of Risks. We would like to express our sincere gratitude to all the referees and also to Mogens Steffensen, Martyn Ryttman, Chao Xiao and MDPI for their collaboration during the preparation of this special issue. Most importantly, we would like to thank all the authors for their excellent contributions.

We hope that this special issue will help stimulate research, both theoretical and applied, on this important problem of managing catastrophic and heavy-tailed risks.

(c) 2014 by the authors; licensee MDPI, Basel, Switzerland. This article is an open access article distributed under the terms and conditions of the Creative Commons Attribution license (http://creativecommons.org/licenses/by/4.0/). 